\title{
PENENTUAN JENIS KERUSAKAN JALAN DENGAN METODE VISUAL DAN IRI (STUDI KASUS:JALAN RAYA TROSOBO KM 22 - 36, KECAMATAN TAMAN)
}

\author{
Andini Rizki Febriana) ${ }^{1)}$ dan Ronny Durrotun Nasihien ${ }^{2)}$
}

${ }^{1)}$ Prodi Teknik Sipil, Universitas Narotama Surabaya, andinimoediono@gmail.com
${ }^{2}$ Prodi Teknik Sipil, Universitas Narotama Surabaya, ronny.durrotun@narotama.ac.id

\begin{abstract}
ABSTRAK
Ketersedian informasi aktual akan kerusakan jalan sangat dibutuhkan untuk mengetahui kondisi suatu jalan baik untuk memantau kondisi jalan maupun perencanaan perbaikan atau Overlay perkerasannya. Informasi yang selama ini sudah akan disusun menjadi sebuah sistem informasi. Sistem informasi kerusakan jalan yang dibuat menggunakan Sistem Informasi Geografi (SIG).Pembuatan Permodelan ini menggunakan perangkat lunak citra satelit Google Earth, pemanfaatan Microsoft Office 2007, Google Map untuk menggambarkan dan mengolah data yang diperoleh langsung dari survey koordinat ruas jalan yang akan dibangun sebagai suatu sistem informasi.Permodelan SIG ini dapat menampilkan informasi ruas jalan yang menginformasikan kondisi kerusakan jalan. Diharapkan dengan pengerjaan tugas akhir Permodelan Kerusakan Jalan, Berbasis Sistem Informasi Geografis (SIG) Di Balai Besar Pelaksanaan Jalan Nasional VIII, ini dapat membantu / mempermudah klarifikasi, jenis dan kategori kerusakan jalan.
\end{abstract}

Kata Kunci : SIG, Kerusakan Jalan, Jenis Kerusakan Jalan;

\section{ABSTRACT}

The availability of actual information on road damage is needed to determine the condition of a road either to monitor road conditions or to improve planning. Information that has been there will be compiled into an information system. Road damage information system created using Geographic Information System (GIS). This modeling using the Google Earth satellite imagery software, the utilization of Microsoft Office 2007, Google Map to describe and process data obtained directly from the survey of the coordinates of the road segment to be constructed as a Information systems. GIS modeling can display road information that informs the road damage condition. It is expected that with the final project of Road Damage Modeling, Based on Geographic Information System (GIS) at Balai Besar Pelaksanaan Jalan nasional VIII, this can assist / facilitate clarification, type and category of road damage.

Keywords: Geographic Information System (GIS), Road Damage, Pavement Overlay

\section{PENDAHULUAN}

Kabupaten Sidoarjo menjadi salah satu daerah strategis bagi pengembangan perekonomian regional dan merupakan kota yang menjadi jalur alternatif masuknya arus kendaraan dari jalur selatan dan tengah. Ruas jalan Raya Trosobo merupakan jalur paling vital yang selalu di lalui kendaraan tonase besar sampai kecil yang lewat setiap harinya dan terus menerus. Namun kondisi jalan yang selalu di perbarui per tahun selalu 


\section{NAROTAMA JURNAL TEKNIK SIPIL \\ e-ISSN: $2460-3430$ \\ VOLUME 2 NOMOR 2 NOVEMBER 2018}

hasilnya mengalami kerusakan yang bermacam - macam jenisnya. Dari yang ringan hingga yang berat.

\subsection{PERMASALAHAN}

Adapun pendekatan masalah yang dipergunakan dalam penelitian ini adalah sebagai berikut :

a. Bagaimana cara mengetahui tingkat kerusakan jalan ditinjau dari hasil survey jalan dengan cara visual dan pengujian kerataan jalan atau IRI (International Roughness Index)padaruasJalanTrosobo $\mathrm{km} 22-36$ ?

b. Bagaimana cara mengetahui jenis - jenis kerusakan jalan ditinjau dari hasil survey jalan dengan visual dan pengujian kerataan jalan atau IRI (International Roughness Index) pada ruas Jalan Raya Trosobo $\mathrm{km} 22-36$

c. Bagaimana hasil penelitian dari analisa survey kerusakan jalan ditinjau dari hasil survey jalan dengan visual dan pengujian kerataan jalan atau IRI (International Roughness Index) pada ruas Jalan Raya Trosobo km 22 - 36?

\subsection{MAKSUD DAN TUJUAN}

Maksud dan tujuan dari penelitian ini adalah

a. Menjelaskan cara mengklarifikasi kerusakan jalan di tinjau dari hasil survey jalan dengan visual dan pengujian kerataan jalan atau IRI (International Roughness Index) pada ruas jalan Raya Trosobo km $22-36$

b. Menjelaskancara jenis - jenis kerusakanjalan di tinjaudarihasil survey jalandenganvisual danpengujiankerataanjalanatau IRI (International Roughness Index)padaruasjalan Raya Trosobo km $22-36$

c. Menjelaskan hasil penelitian dari analisa kerusakan jalan di tinjau dari hasil survey jalan dengan visual dan pengujian kerataan jalan atau IRI (International Roughness Index)pada ruas jalan Raya Trosobo km 22 - 36.

\section{TINJAUAN PUSTAKA}

Jalan adalah prasarana transportasi darat yang meliput segala bagian jalan, termasuk bangunan pelengkap dan perlengkapannya yang diperuntukkan bagi lalulintas, yang berada pada permukaan tanah, di atas permukaan tanah, di bawah permukaan tanahdan/atau air, serta di atas permukaan air, kecuali jalan kereta api, jalan lori, dan jalan kabel.

Secara teknis, kerusakan jalan menunjukkan suatu kondisi dimana structural dan fungsional jalan sudah tidak mampu memberikan pelayanan optimal terhadap lalulintas yang melintasi jalan tersebut. Kondisi lalulintas dan jenis kendaraan yang akan melintasi suatu jalan sangat berpengaruh pada desain perencanaan konstruksi dan perkerasan jalan yang dibuat.

Menurut Manual Pemeliharaan Jalan Bina Marga No. 03/MN/B/1983, kerusakan jalan diklasifikasikan atas :retak (cracking), distorsi, cacat permukaan (disintegration), pengausan (polish aggregate), kegemukan (bleedingatauflushing), penurunan bekas galian/penanaman utilitas.

a. $\operatorname{Retak}($ Crack) 


\section{NAROTAMA JURNAL TEKNIK SIPIL \\ e-ISSN: 2460-3430 \\ VOLUME 2 NOMOR 2 NOVEMBER 2018}

Retak adalah suatu gejala kerusakan permukaan perkerasan sehingga akan menyebabkan air pada permukaan perkerasan masuk ke lapisan dibawahnya dan hal ini merupakan salah satu faktor yang akan membuat luas/parah suatu perkerasan (DepartemenPekerjaan Umum, 2007).Jenis-jenis retak(crack) antara lain retakhalus (hair cracking), retak kulit buaya (alligator cracks), retak pinggir (edge crack), retaksambungan(edge joint crack), retaksambunganjalan(lane joint crack), retak sambungan pelebaran jalan (widening crack), retakrefleksi (reflection crack), retaksusut(shrinkage crack)danretakselip (slippage crack).

b. Distorsi(Distotion)

Jenis kerusakan lentur atau fleksibel berupa distorsi dapat terjadi atas lemahnyatanah dasar, pemadatan yang kurang pada lapis pondasi sehingga terjadi tambahan pemadatan akibat beban lalu lintas. Untuk kerusakan jalan yang satu ini dibagi atas beberapa jenis diantaranyaalur(ruts), keriting (corrugation), sungkur(shoving), amblas(grade depression), jembul(upheaval).

c. CacatPermukaan (Disintegration)

Jenis kerusakan yang satu ini mengarah pada kerusakan secara kimiawi \&mekanis dari lapisan permukaan, yang termasuk cacat permukaan adalah lubang(potholes), pelepasan butir(raveling), pengelupasan lapisan perkerasan (stripping).

d. Pengausan(Polish Aggregate)

Pengausan terjadi karena agregat berasal dari material yang tidak tahan aus terhadap roda kendaraan / agregat yang digunakan berbentuk bulat dan licin.Dapat diatasi dengan latasir, buras, latasbum.

e. Kegemukan(Bleeding/Flushing)

Pada temperatur tinggi, aspal menjadi lunak, dan akan terjadi jejak roda, dapatdisebabkan pemakaian kadar aspal yang tinggi pada campuran aspal, pemakaian terlalu banyak aspal pada pengerjaan prime coat / teak coat. Dapat diatasi dengan menaburkan agregat panas dan kemudian dipadatkan, atau lapis aspal diangkat dan diberi lapisan penutup.

International Roughness Index (IRI) adalah parameter yang digunakan untuk menentukan tingkat ketidakrataan permukaan jalan. Parameter Roughness dipresentasikan dalam suatu suatu skala yang menggambarkan ketidakrataan permukaan perkerasan jalan yang dirasakan pengendara. Ketidakrataan permukaan perkerasan jalan tersebut merupakan fungsi dari potongan memanjang dan melintang permukaan jalan. Roughness juga dipengaruhi oleh faktor-faktor lain seperti operasional kendaraan, yang meliputi suspensi roda, bentuk kendaraan, kedudukan kerataan kendaraan serta kecepatan. 


\section{NAROTAMA JURNAL TEKNIK SIPIL \\ e-ISSN: 2460-3430 \\ VOLUME 2 NOMOR 2 NOVEMBER 2018}

\section{METODE PENELITIAN}

Perumusan metodologi penelitian dalam pelaksanaan penelitian ini adalah sebagai berikut:

1) ObyekSurvei

Obyek yang dikaji dalam penelitian ini adalah letak geografis pada ruas Taman Km 22 sampai ruas Balongbendo Km 36 di Wilayah Balai Besar Pelaksanaan Jalan Nasional VIII yang terdapat di wilayahProvinsiJawaTimur.

2) MetodePengumpulan Data

Metode pengumpulan data adalah cara pengadaan atau pengumpulan data yang digunakan untuk keperluan dan pelaksanaan penelitian. Metode pengumpulan data yang digunakanyaitu :

a. MetodeObservasi

Metode ini melakukan pengamatan langsung di lapangan ehingga dapat diperoleh gambaran sertain formasi yang lebih jelas untuk bahan dalam menyusun laporan penelitian.

b. MetodePustaka(Literatur)

Metode ini dilakukan dengan mengambil bahan dari buku Literatur sebagai bahan acuan pelengkap di dalam penyusunan laporan ini.

c. MetodeDokumentasi

Dokumentasi digunakan untuk memperoleh data pelengkap berupa gambar yang ada pada saat pelaksanaan pekerjaan.

Metode pengumpulan data yang diterapkan dalam penelitian ini adalah penelitian survey dengan metode pengumpulan data primer dan pengumpulan data sekunder.Pengumpulandata primer dilakukan survey koordinat dan dokumentasi kerusakan jalan yang meliputi ruas ruas jalan raya Trosobo $\mathrm{Km} 22-36$.Sebagai data sekunder yaitu data yang meliputidata IRI(International Roughness Index). 
Adapun tahapan pelaksanaan penelitian dapat dilihat pada bagan alir dibawah ini :

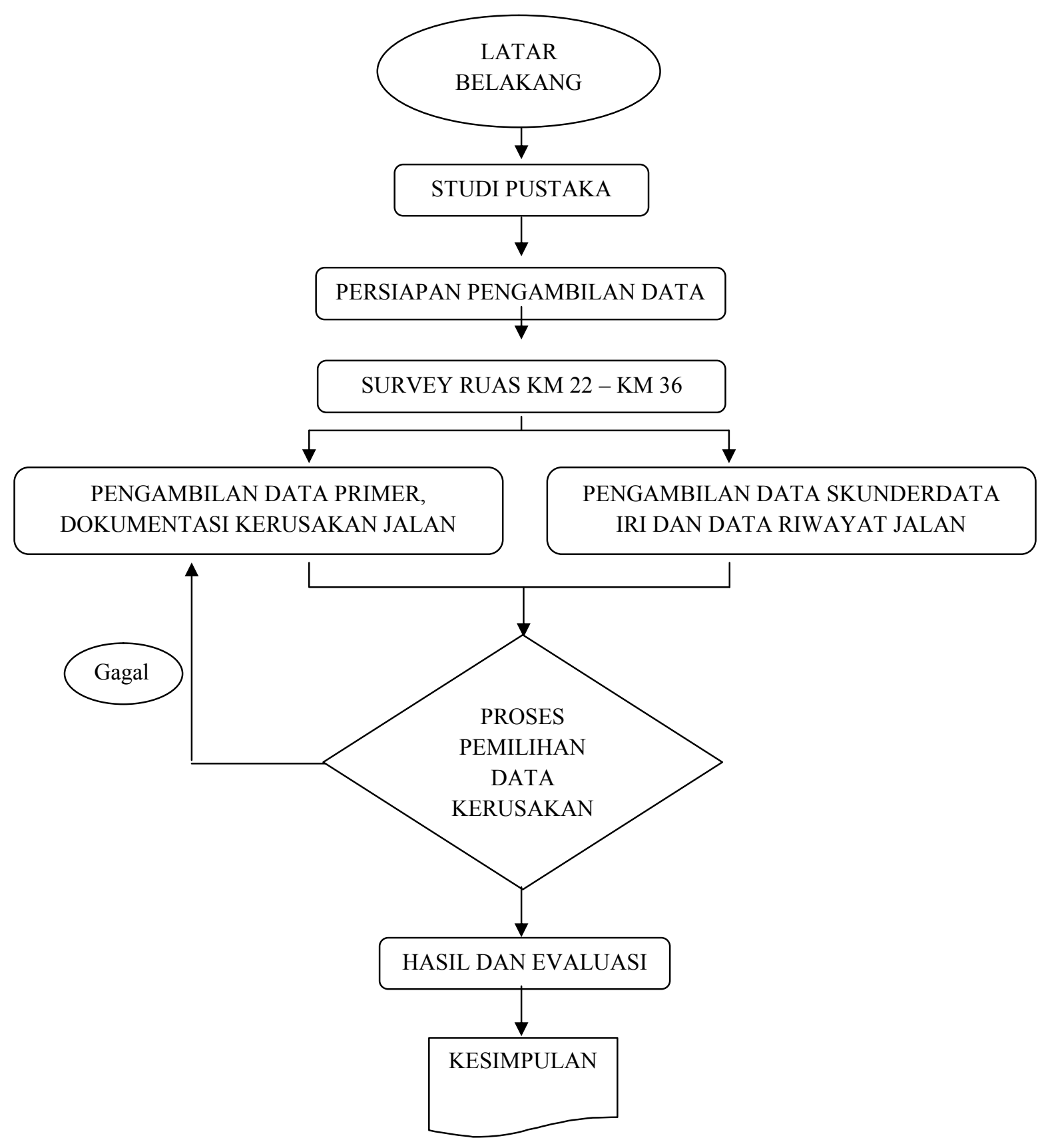

Gambar 1. Diagram Alir Penelitian 


\section{HASIL DAN PEMBAHASAN}

Dari hasil pengamatan yang dilakukan di ruas jalan Raya Trosobo Km 22 - 36, maka di hasilkan jenis - jenis kerusakan jalan yang dapat digolongkan dengan jenis kerusakan ringan, sedang ataupun berat. Maka dalam hal ini di rangkum dalam sebuah tabel dan digolongkan jenis kerusakan jalan, sebagai berikut:

Tabel 1. JenisKerusakanjalan Raya Trosobo Km 22+000 s.d 36+000

\begin{tabular}{|c|c|c|c|c|c|}
\hline \multirow[t]{2}{*}{ NO } & \multirow[t]{2}{*}{ JENIS KERUSAKAN JALAN } & \multirow[t]{2}{*}{ STA / KM } & \multicolumn{3}{|c|}{$\begin{array}{l}\text { GOLONGAN KERUSAKAN } \\
\text { JALAN }\end{array}$} \\
\hline & & & RINGAN & SEDANG & BERAT \\
\hline 1 & RETAK ALUR & $22+000$ & $\mathrm{~V}$ & - & - \\
\hline 2 & BLEEDING PINGGIR & $22+100$ & $\mathrm{~V}$ & - & - \\
\hline 3 & RETAK BUAYA & $22+120$ & $\sqrt{ }$ & - & - \\
\hline 4 & RETAK PINGGIR (BAHU JALAN) & $22+160$ & $\mathrm{~V}$ & - & - \\
\hline 5 & RETAK BUAYA & $22+900$ & $\sqrt{ }$ & - & - \\
\hline 6 & RETAK ALUR & $23+000$ & $\mathrm{~V}$ & - & - \\
\hline 7 & BLEEDING PINGGIR & $23+100$ & $\sqrt{ }$ & - & - \\
\hline 8 & $\begin{array}{c}\text { RETAK BUAYA \& LUBANG } \\
\text { MEMANJANG }\end{array}$ & $23+550$ & - & $\sqrt{ }$ & - \\
\hline 9 & BLEEDING PINGGIR & $23+750$ & $\sqrt{ }$ & - & - \\
\hline 10 & ASPAL AUS (AGREGAT TERLIHAT) & $23+900$ & $\sqrt{ }$ & - & - \\
\hline 11 & DEFORMASI ALUR & $24+050$ & $\mathrm{~V}$ & - & - \\
\hline 12 & JALAN GELOMBANG & $24+150$ & $\sqrt{ }$ & - & - \\
\hline 13 & LUBANG \& RETAK & $24+200$ & - & $\sqrt{ }$ & - \\
\hline 14 & DEFORMASI & $24+350$ & - & $\sqrt{ }$ & - \\
\hline 15 & ASPAL TERKELUPAS & $24+450$ & - & $\sqrt{ }$ & - \\
\hline 16 & RETAK ALUR & $24+800$ & - & $\sqrt{ }$ & - \\
\hline 17 & ASPAL AUS (AGREGAT TERLIHAT) & $25+300$ & $\sqrt{ }$ & - & - \\
\hline 18 & BLEEDING PINGGIR & $25+350$ & $\sqrt{ }$ & - & - \\
\hline 19 & $\begin{array}{l}\text { PATCHING TIDAK RATA } \\
\text { (BERGELOMBANG) }\end{array}$ & $25+600$ & - & $\sqrt{ }$ & - \\
\hline 20 & ASPAL TERKELUPAS MEMANJANG & $26+000$ & - & $\sqrt{ }$ & - \\
\hline 21 & LUBANG \& RETAK & $26+050$ & - & $\sqrt{ }$ & - \\
\hline 22 & LUBANG \& RETAK & $26+070$ & - & $\sqrt{ }$ & - \\
\hline 23 & LUBANG \& RETAK & $26+090$ & - & $\sqrt{ }$ & - \\
\hline 24 & LUBANG \& RETAK & $26+165$ & - & $\sqrt{ }$ & - \\
\hline 25 & RETAK BUAYA & $26+215$ & $\mathrm{~V}$ & - & - \\
\hline 26 & LUBANG \& RETAK & $26+600$ & - & $\sqrt{ }$ & - \\
\hline 27 & BERGELOMBANG & $27+100$ & $\sqrt{ }$ & - & - \\
\hline 28 & RETAK \& LUBANG & $28+050$ & $\mathrm{~V}$ & - & - \\
\hline 29 & ASPAL DI BAHU JALAN TIDAK RATA & $28+400$ & $\sqrt{ }$ & - & - \\
\hline 30 & RETAK ALUR & $28+700$ & $\sqrt{ }$ & - & - \\
\hline 31 & RETAK BUAYA & $29+500$ & $\mathrm{~V}$ & - & - \\
\hline
\end{tabular}


NAROTAMA JURNAL TEKNIK SIPIL

e-ISSN: $2460-3430$

VOLUME 2 NOMOR 2 NOVEMBER 2018

\begin{tabular}{|c|c|c|c|c|c|}
\hline \multirow[t]{2}{*}{ NO } & \multirow[t]{2}{*}{ JENIS KERUSAKAN JALAN } & \multirow[t]{2}{*}{ STA / KM } & \multicolumn{3}{|c|}{$\begin{array}{c}\text { GOLONGAN KERUSAKAN } \\
\text { JALAN }\end{array}$} \\
\hline & & & RINGAN & SEDANG & BERAT \\
\hline 32 & JALAN GELOMBANG & $31+100$ & $\sqrt{ }$ & - & - \\
\hline 33 & $\begin{array}{c}\text { DEFORMASI MEMANJANG \& } \\
\text { BLEEDING }\end{array}$ & $31+200$ & - & $\sqrt{ }$ & - \\
\hline 34 & RETAK BUAYA & $31+275$ & $\sqrt{ }$ & - & - \\
\hline 35 & LUBANG \& RETAK & $31+375$ & - & $\sqrt{ }$ & - \\
\hline 36 & BLEEDING & $31+500$ & - & $\sqrt{ }$ & - \\
\hline 37 & DEFORMASI & $31+600$ & - & $\sqrt{ }$ & - \\
\hline 38 & JALAN BERLUBANG & $31+700$ & - & - & $\sqrt{ }$ \\
\hline 39 & DEFORMASI \& RETAK BUAYA & $31+750$ & - & $\mathrm{V}$ & - \\
\hline 40 & DEFORMASI & $31+850$ & - & $\sqrt{ }$ & - \\
\hline 41 & DEFORMASI \& BLENDING & $33+100$ & - & $\sqrt{ }$ & - \\
\hline 42 & BLEEDING & $33+200$ & - & $\sqrt{ }$ & - \\
\hline 43 & JALAN BERLUBANG & $33+275$ & - & $\mathrm{V}$ & - \\
\hline 44 & JALAN BERLUBANG & $33+300$ & - & $\sqrt{ }$ & - \\
\hline 45 & JALAN BERLUBANG & $33+400$ & - & $\mathrm{V}$ & - \\
\hline 46 & BLEEDING \& JALAN BERLUBANG & $33+450$ & - & $\mathrm{V}$ & - \\
\hline 47 & JALAN BERLUBANG \& RETAK BUAYA & $33+650$ & - & $\sqrt{ }$ & - \\
\hline 48 & JALAN BERLUBANG \& RETAK BUAYA & $33+700$ & - & $\mathrm{V}$ & - \\
\hline 49 & JALAN BERLUBANG \& RETAK BUAYA & $33+800$ & - & $\sqrt{ }$ & - \\
\hline 50 & JALAN BERLUBANG \& RETAK BUAYA & $33+880$ & - & $\mathrm{V}$ & - \\
\hline 51 & JALAN BERLUBANG \& RETAK BUAYA & $33+900$ & - & $\mathrm{V}$ & - \\
\hline 52 & JALAN BERLUBANG \& ASPAL AUS & $35+200$ & - & $\sqrt{ }$ & - \\
\hline 53 & JALAN BERLUBANG \& RETAK BUAYA & $35+900$ & - & $\mathrm{V}$ & - \\
\hline 54 & JALAN BERLUBANG \& RETAK BUAYA & $36+000$ & - & $\sqrt{ }$ & - \\
\hline
\end{tabular}

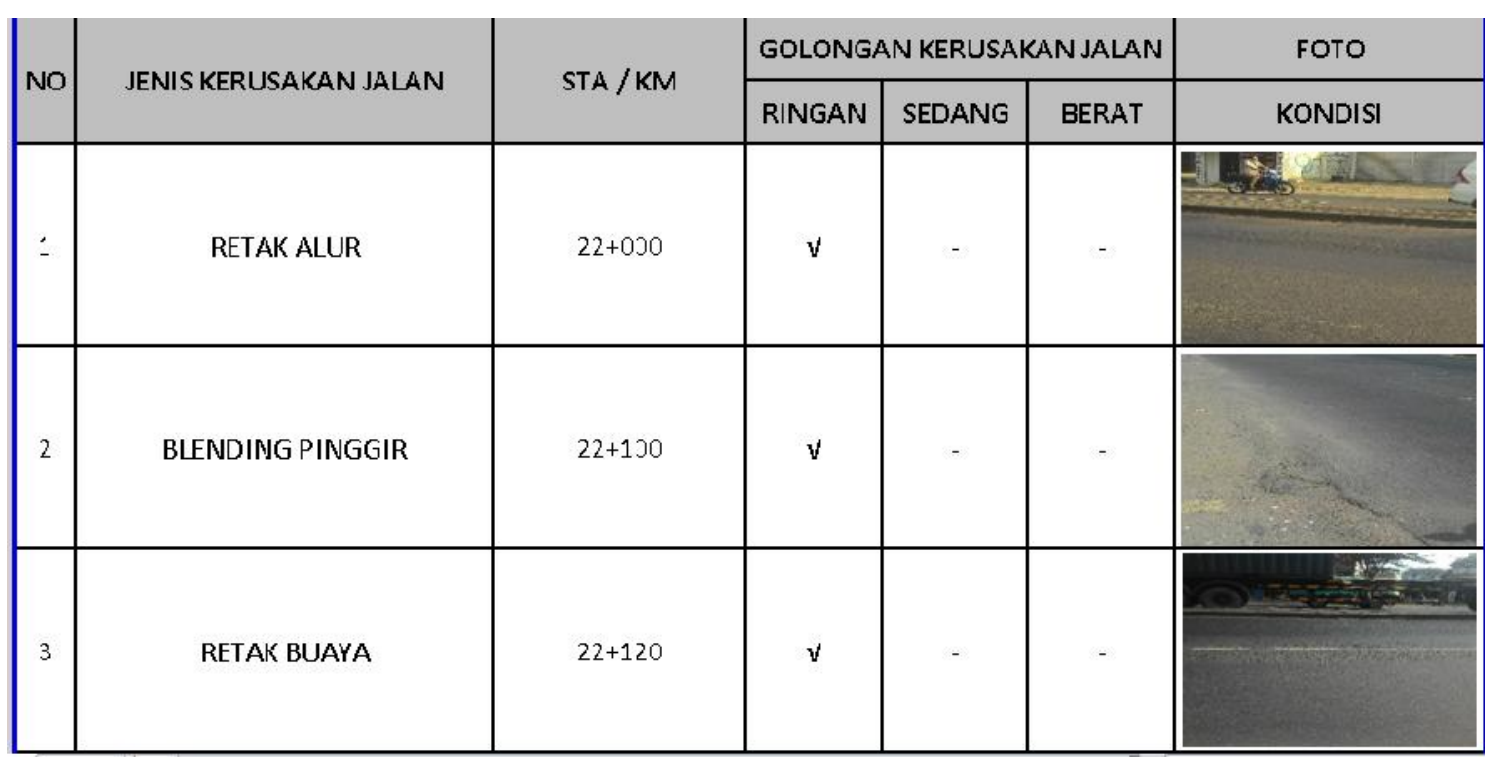

Gambar 2. Dokumentasi kerusakan jalan pada satu ruas penelitian 


\section{NAROTAMA JURNAL TEKNIK SIPIL \\ e-ISSN: 2460-3430 \\ VOLUME 2 NOMOR 2 NOVEMBER 2018}

Setelah dilakukan survey dan mengambil data primer yang dibutuhkan, maka hal selanjutnya ialah mencari data NAASRA/ IRI (International Roughness Index) guna melengkapi data yang berhubungan dengan penelitian, dalamhalini data IRI (International Roughness Index) sangat berguna bagi peneliti karena data IRI (International Roughness Index) berhubungan dengan tingkat kenyamanan berkendara dan tingkat kenyamanan pengguna jalan sehingga sangat dibutuhka nkarena IRI (International Roughness Index) sendiri merupakan nila ikerataan jalan, jadi seberapa tingkat kerataan jalan yang ada di ruas Trosobo sampai Balongbendo.

Kerataan permukaan lapis perkerasan penutup atau lapis aus diuji dengan menggunakan alat ukur NAASRA meter sesuai SNI 02-3426-1994 dengan nilai IRI (International Roughness Index) paling tidak 3. Setelah di dapat nilai IRI (International Roughness Index) maka dapat disimpulkan bahwa nilai IRI pada ruas Trosobo sampai dengan Balongbendo rata - rata adalah rusak sedang.

Tabel 2. Parameter Nilai IRI UntukKerataanJalan

\begin{tabular}{|c|c|c|c|}
\hline $\begin{array}{c}\text { Roughness } \\
\text { Category }\end{array}$ & $\begin{array}{c}\text { IRI } \\
\text { (Metric) }\end{array}$ & $\begin{array}{c}\text { IRI } \\
\text { (Imperial) }\end{array}$ & $\begin{array}{c}\text { NAASRA } \\
\text { (Metric) }\end{array}$ \\
\hline Very Good & $0-2$ & $0-157$ & $0-52$ \\
\hline Good & $3-4$ & $158-284$ & $78-105$ \\
\hline Fair & $5-6$ & $285-411$ & $131-158$ \\
\hline Poor & $7-10$ & $412-664$ & $184-264$ \\
\hline Bad & $11+$ & $665+$ & $290+$ \\
\hline
\end{tabular}

Berikut ini merupakan salah satu contoh perhitungan kerusakan jalan dengan menggunakan IRI diambil pada titik kilometer $24-25$ :

Field Data Sheet

ROAD NAME

SECTION

SURVEY DATE

TRAVEL DIRECTION

REFERENCE

VEHICLE

OPERATOR

LEAD IN

COMMENTS

\section{JALAN RAYA TROSOBO}

FROM: $24+000$ TO: $25+000$

2017-03-30 TIME: 08:40:37

FORD RANGER

ARIF

$49 \mathrm{~m}$ 


\begin{tabular}{|c|c|c|c|c|c|}
\hline \multicolumn{2}{|c|}{ Roughness Value } & \multirow[b]{2}{*}{ TotDist } & \multirow[b]{2}{*}{ IRI } & \multirow[b]{2}{*}{ Speed } & \multirow[b]{2}{*}{ Events } \\
\hline Section & SubDist & & & & \\
\hline 1 & 0.100 & 0.100 & 7.1 & 45.3 & \\
\hline 1 & 0.200 & 0.200 & 5.4 & 45.1 & \\
\hline 1 & 0.300 & 0.300 & 5.8 & 44.5 & \\
\hline 1 & 0.400 & 0.400 & 8.8 & 48.8 & \\
\hline 1 & 0.500 & 0.500 & 9.7 & 48.4 & \\
\hline 1 & 0.600 & 0.600 & 9.4 & 48.7 & \\
\hline 1 & 0.700 & 0.700 & 13.5 & 48.1 & \\
\hline 1 & 0.800 & 0.800 & 12.6 & 47.6 & \\
\hline 1 & 0.900 & 0.900 & 7.7 & 48.4 & \\
\hline 1 & 1.000 & 1.000 & 7.4 & 48.1 & \\
\hline
\end{tabular}

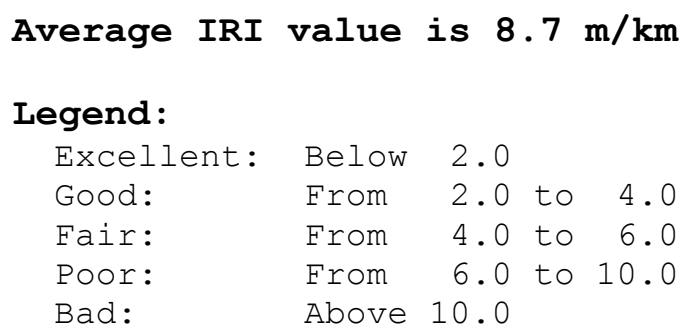

Data di atas merupakan contoh sampel yang diambil pada ruas Jalan Raya Trosobo km 24 - 25. Dari contoh tersebut nilai IRI (International Roughness Index) yang didapat terlihat bahwa ada beberapa STA yang mengalami kerusakan berat. Namun, setelah dihitung rata - ratanya maka didapatkan nilai $8,7 \mathrm{~m} / \mathrm{km}$ yang artinya nilai tersebut masih tergolong rusak sedang. Hasil pada STA lain menunjukkan pula bahwa nilai rata-rata hasil pengujian IRI (International Roughness Index) yang didapat dikategorikan rusak sedang (data terlampir).

Hasil survey dan perhitungan IRI kemudian disajikan dalam Sistem Informasi Geografis (SIG) yaitu menggunakan aplikasi Google Earth. Sebelum proses input data keGoogle Earth, terlebih dahulu data informasi yang akan ditampilkan di Google Earth disimpan terlebih dahulu dalam blog yang sebelumnya telah dibuat, karena nantinya tampilan informasiakan disajikan / di link kanke blog tersebut. Data yang tersimpan dalam blog penelitian ini menampilkan informasi dokumentasi kerusakan jalan dan perhitungan untuk overlay perkerasan jalan pada tiap ruas jalan penelitian dan informasi yang disajikan berupa image dengan format *jpg. 


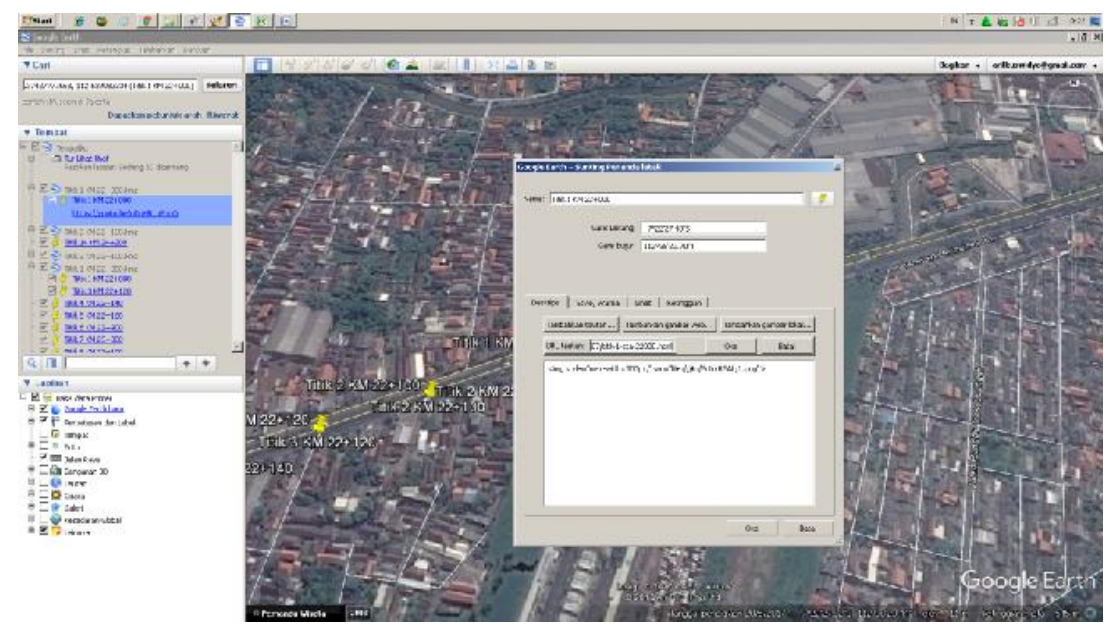

Gambar 3. Cara Memasukkan Foto dan Video di Google Earth

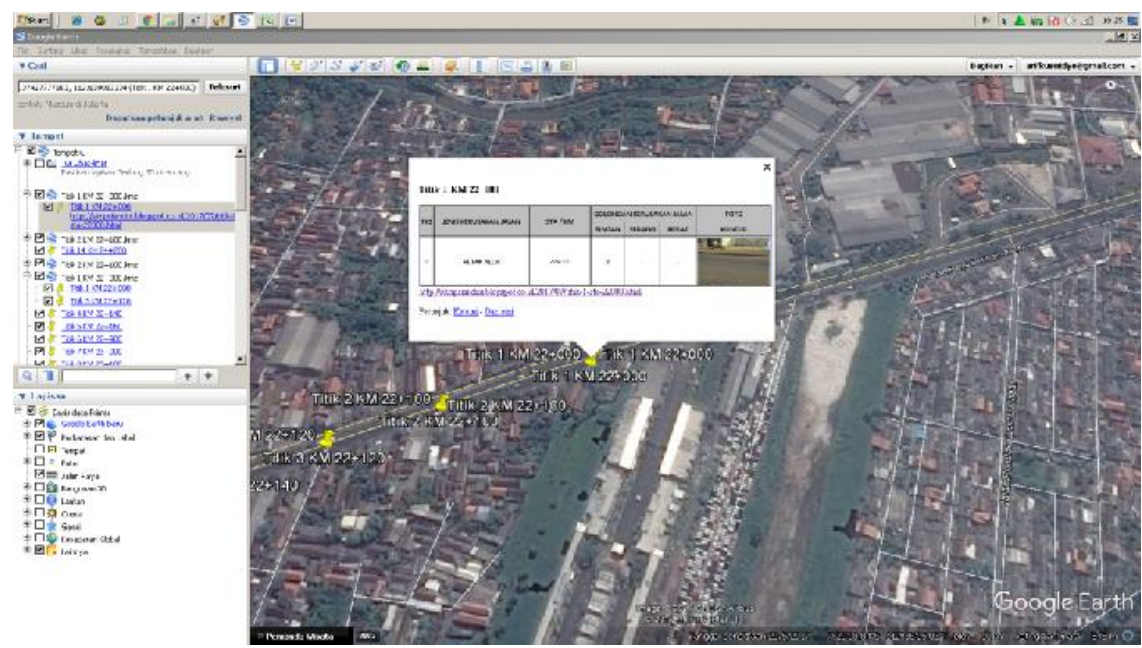

Gambar 4. Hasil Foto dan Keterangan Kerusakan Jalan di Google Earth

Cara memasukkan file video ke blogspot :

1. Masuk ke dashboard Blog, kemudian pilih tombol entri baru

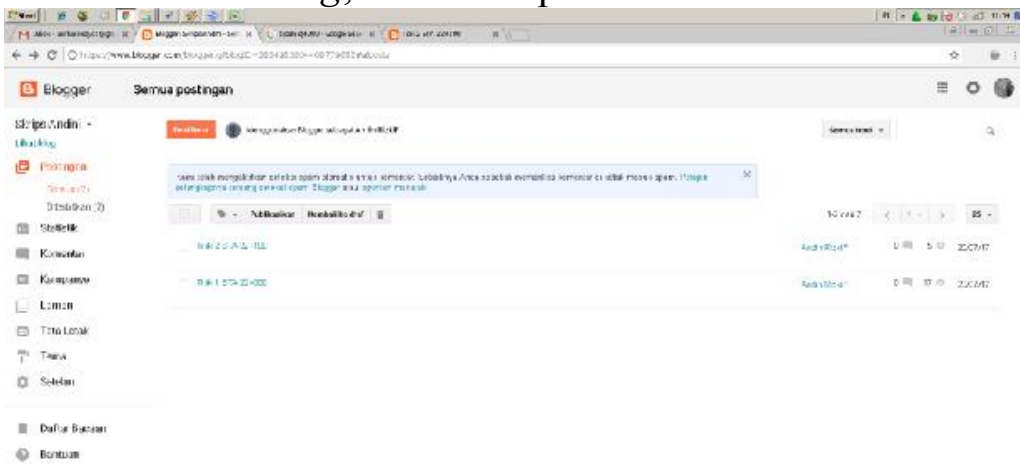

Gambar 5. Tampilan Dashboard pada Blog 
2. Masukkan pilihan judul yang akan di posting, kemudan pilih insert video

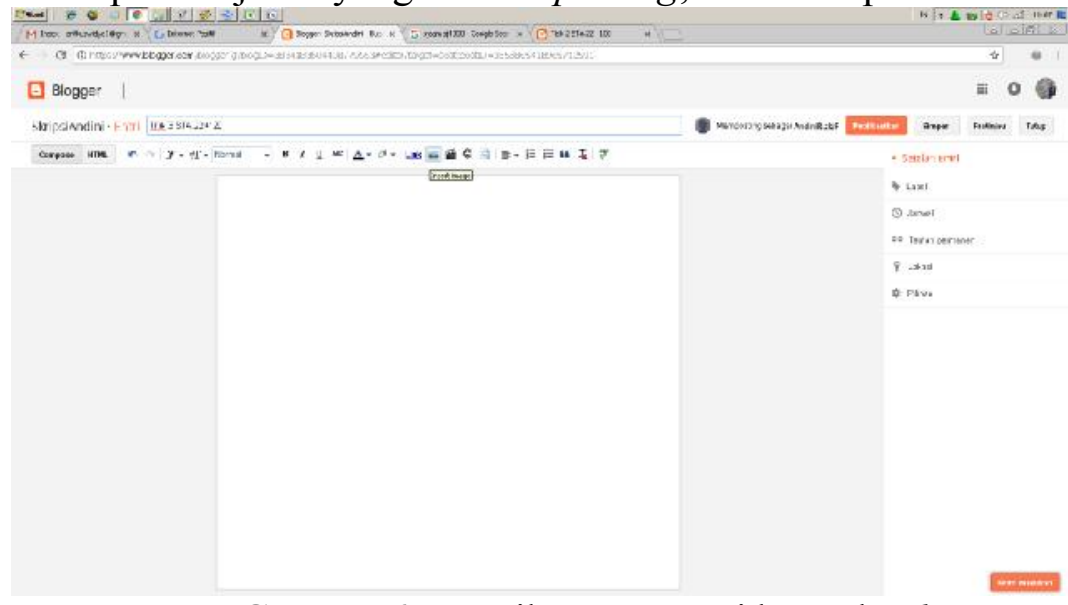

Gambar 6. Tampilan Posting Video pada Blog

3. Pilih video yg akan diupload kemudian pilih open. Tunggu upload file video berhasil. Kemudian pilih tombol publikasikan.

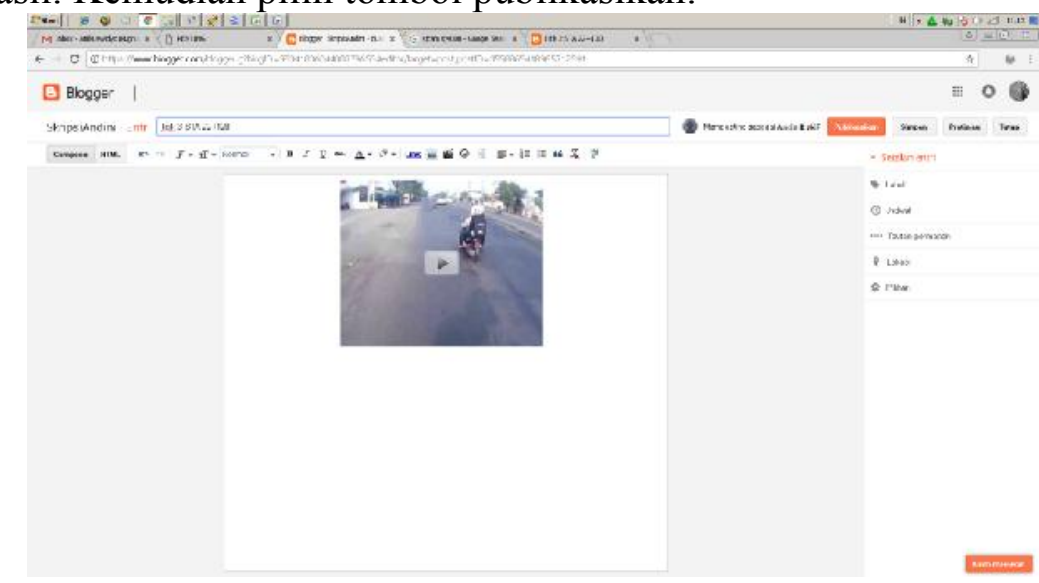

Gambar 7. Tampilan Video yang Telah Di Upload di Blog

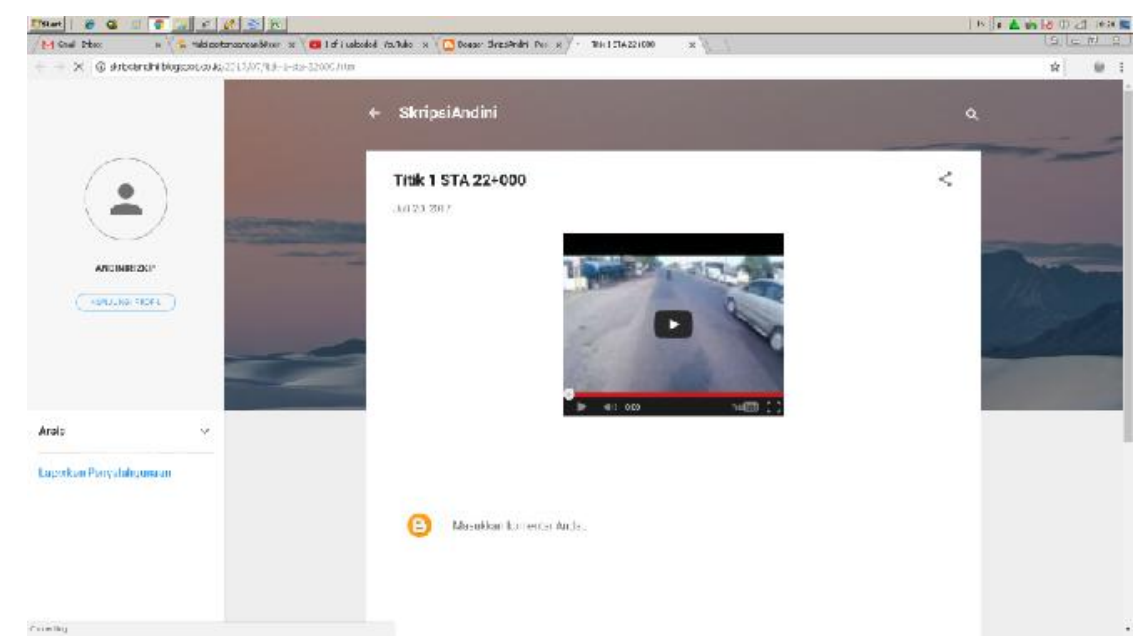

Gambar 8. Hasil Tampilan Video di Blogspot 


\section{NAROTAMA JURNAL TEKNIK SIPIL \\ e-ISSN: 2460-3430 \\ VOLUME 2 NOMOR 2 NOVEMBER 2018}

\section{KESIMPULAN}

Dari hasilpenelitian ini dapat diambil beberapa kesimpulan, diantaranya :

a. Dalam penelitian yang dilaksanakan dalam penelitian ini menghasilkan suatu model monitoring dan evaluasi yang didalamnya dapat menampilkan informasi kerusakan jalan serta perhitungan overlay perkerasan dengan umur rencana 5 tahun.

b. Untuk perhitungan overlay perkerasan lentur menghasilkan nilai tebal lapis tambah pada tiap ruas penelitian.

\section{SARAN}

a. Dari kesimpulan di atas, penulis menyarankan untuk selanjutnya diharapkan selalu diadakan pembaruan dan perbaikan data, baik data primer maupun data sekunder, sehingga informasi data yang tersedia selalu up to date.

b. Input data dalam permodelan ini masih bersifat manual,untuk pengembangan selanjutnya penulis berharap dapat mengembangkan permodelan ini agar menjadi suatu aplikasi yang bisa diinput secara langsung dalam aplikasi tersebut.

\section{DAFTAR PUSTAKA}

1. Aini, Anisah. Sistem Informasi Geografis Pengertian dan Aplikasinya. Yogyakarta.

2. Bolla, Magareth Evelyn. Perbandingan Metode Bina Marga dan Metode PCI (Pavement Condition Index) Dalam Penilaian Kondisi Perkerasan Jalan (Studi Kasus Jalan Kaliurang, Kota Malang). Kupang, Nusa Tenggara Timur.

3. Departemen Pekerjaan Umum (1995). Manual Pemeliharaan Rutin untuk Jalan Nasional dan Jalan Propinsi, Jilid II : Metode Perbaikan Standar.

4. Direktorat Jenderal Bina Marga (1990). Tata Cara Penyusunan Program Pemeliharaan Jalan Kota, No. 018/T/BNK/1990.

5. $\quad$ ESRI (1991)., Arc/Info : Data Mode, Concepts\&Key Terms

6. Irwansyah, Edi (2013). Sistem Informasi Geografis: Prinsip Dasar dan Pengembangan Apilkasi.Yogyakarta.

7. Kementerian Pekerjaan Umum (2010, Revisi III). Dokumen Pelelangan Nasional : Penyediaan Pekerjaan Konstruksi (Pemborongan) untuk Kontrak Harga Satuan (Bab III : Spesifikasi Umum).

8. Siahaan, Doan Arinata. Surbakti, Medis S. Analisis Perbandingan Nilai IRI Berdasarkan Variasi Rentang Pembacaan NAASRA. Medan.

9. Suroso, Tjitjik Warsiah (2008). Faktor-faktor Penyebab Kerusakan Dini Pada Perkerasan Jalan. Bandung.

10. Tata Cara Survei Kerataan Permukaan Perkerasan Jalan dengan Alat Ukur Kerataan NAASRA. SNI 03-3426-1994. 